\title{
LA ÉTICA Y VALORES EN ENFERMERÍA
}

\section{Ethics and Values in Nursing}

\author{
Dra. Isabel Natividad Urure Velazco ${ }^{1}$
}

\footnotetext{
${ }^{1}$ Profesor Principal de la Facultad de Enfermería, Universidad Nacional San Luis Gonzaga de Ica, Perú Editora en Jefe de la Revista Enfermería a la Vanguardia. Ica, Perú
}

Hablar de ética y valores es referirnos a dos conceptos tan íntimamente relacionados de manera que el comportamiento ético de una persona depende de su formación de valores, esta premisa según revisión bibliográfica, señala que "la ética personal surge de los valores personales" (1).

Definiéndose la ética como las reglas o principios que gobiernan la conducta correcta (2), y los valores que son principios que nos permiten orientar nuestro comportamiento en función de realizarnos como personas. Así como lo expresa Kozier, que "los valores dan dirección y significado a la vida y guían el comportamiento de una persona" (2).

Y al referirnos a la ética y valores en enfermería, se ha concebido siempre estos conceptos una gran relevancia, ya que su aplicación está vinculado al quehacer diario en la que se apoya sus atributos, actitudes, comportamiento en la acción de cuidar. En este sentido "en el caso de las instituciones de educación superior de enfermería, el interés por la formación de valores, parte de que tienen como misión formar profesionales de enfermería humanistas, con capacidad innovadora, reguidos por el pensamiento crítico, que sean líderes en el cuidado profesional" (3)..

Asimismo "el pensamiento crítico es una parte importante del procesamiento de dilemas éticos" (1), es decir que nos permite solucionar en las mejores condiciones los problemas que se presentan en el quehacer profesional cotidiano.

La profesión de enfermería requiere del conocimiento de diversas ciencias para brindar los cuidados a los seres humanos que es la esencia de la profesión, pero también es de vital importancia que incorpore, equilibradamente los principios éticos y morales en su actuar profesional y personal, para así poder asistir y brindar cuidados de manera integral y/o holística. Para cumplir a cabalidad el objetivo de cuidar, se requiere de una base sólida de la formación moral de valores éticos personales y profesionales conducentes a mejorar la salud de las personas, etc.

Hoy en día vivenciamos una crisis de valores, este mundo globalizado ha trastocado las relaciones humanas, dejando atrás los principios morales, la esencia espiritual del hombre y aún más del profesional de enfermería que por su naturaleza, tiene que dar cuidados a seres humanos. De esta manera "el conocimiento y la formación ética del profesional de enfermería debe fortalecerse durante sus etapas de formación, tanto en pregrado como en postgrado, ya que el enfermero trabaja bajo la influencia de una escala de valores profesional y personal, cuando entra en relación con los pacientes, y en algunos momentos los valores del profesional de enfermería pueden entrar en conflicto con los del paciente" (4).

En este contexto debe ser un compromiso como profesionales de enfermería fortalecer día a día nuestros valores éticos personales y profesionales, teniendo como base la parte espiritual que se reflejará en nuestro actuar al entablar relaciones humanas con el paciente, que es el que recibe nuestros cuidados y con las demás personas en convivencia con la sociedad. 


\section{REFERENCIAS BIBLIOGRÁFICAS.}

1. Potter P., Perry A. Fundamentos de Enfermería $6^{a}$ ed. Volumen I. Madrid, España. Ed. Grafos; 2007.

2. Kozier B; Erb Gle; Bufalino P. Fundamentos de Enfermería. México: Ed. Interamericana McGraw-Hill. 2001

3. Díaz M; Castro D; Cuevas J. Valores profesionales de enfermería: Una mirada hacia la formación en la Educación Superior. Estado de México, México. Rev. Humanidades Médicas. 2012; 12 (2): 292

4. Hernández A. Algunas consideraciones acerca de los valores humanos del profesional de enfermería. Colombia. Rev. Aquichán. 2001; 1(1):18 